\title{
Epidemiological study of incidence and risk factors of Ischemic stroke subtypes according to Trial of ORG 10172 in acute stroke treatment criteria: A 3 years, hospital-based study
}

Pushpendra Nath Renjen, Mirza Atif Beg', Kamal Ahmad

Department of Neurosciences, Indraprastha Apollo Hospital, Sariat Vihar, New Delhi, 'Department of Pharmacology, SGRRIM\&HS, Patel Nagar,

Dehradun, Uttarakhand, India

Address for the Correspondence: Dr. Mirza Atif Beg, Department of Pharmacology, SGRRIM\&HS, Patel Nagar, Dehradun, Uttarakhand - 248001, India.

E-mail: mabeg1997@gmail.com

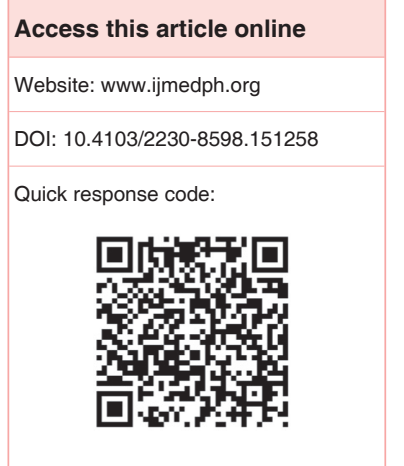

Background and Purpose: The purpose of this study was to determine the incidence and risk factor of ischemic stroke subtypes by a mechanismbased classification scheme (Trial of ORG 10172 in Acute Stroke Treatment [TOAST]). Materials and Methods: This study was conducted in Indraprastha Apollo Hospital, New Delhi, between 01/01/2004 and 31/12/2006. Out of 361 admitted stroke patients, 244 (67.59\%) ischemic stroke patients were analyzed retrospectively for incidence and modifiable risk factors for stroke in our region. The cause of ischemic stroke was classified according to the TOAST criteria. Results: Out of 244 patients $165(67.6 \%)$ were male and $79(32.4 \%)$ were female, the mean age at the time of stroke was 57.1 years, the incidence of different risk factors were as follows: 139 (56.9\%, odds ratio $2.71)$ hypertensive, 85 (34.8\%, odds ratio 2.4$)$ diabetics, 95 (38.9\%, odds ratio 3.12$)$ smokers, 58 (23.7\%, odds ratio 5.34) dyslipidemics, $44(18.0 \%$, odds ratio 1.43$)$ coronary artery disease (CAD) patients, $14(5.7 \%$, odds ratio 1.22) patients have the transient ischemic stroke in the past, $13(5.3 \%$, odds ratio 1.43) were given the history of atrial fibrillation. The incidence rates of ischemic stroke subtypes were as follows: Determined causes; large artery atherosclerosis 141 (57.7\%), lacunes 18 (7.7\%), cardio-embolism 11 (4.5\%), hypercoagulable state $8(3.2 \%)$, un-determined causes; atherosclerosis and/or lacunes 25 (10.2\%), embolism and/or two more (hypercoagulable state/CAD) possible causes $7(2.8 \%)$, negative evaluation in $34(13.9 \%)$ patients. Ischemic stroke subtype according to the TOAST criteria was a significant predictor for long-term survival. Conclusions: Our data indicate that large vessel disease is a major cause, and the hypertension, diabetes, smoking, hyperlipidemia are the most common risk factors for Ischemic stroke.

Key words: Epidemiology, incidence, risk factors, stroke classification

\section{INTRODUCTION}

Stroke remains the most common life-threatening neurological disease globally and impacts individuals, their families and society. ${ }^{[1,2]} \mathrm{It}$ is the leading cause of disability among elderly and the second leading cause of mortality worldwide. ${ }^{[3]}$ Stroke is responsible for millions of deaths in developing countries, ${ }^{[4]}$ and is the major cause of mortality and morbidity in Asian countries. Treatment options are limited to thrombolysis, but only few patients receive this treatment owing to restrictions in application time and indication. ${ }^{[5]}$ Thus, primary prevention remains the most important general strategy for reducing the impact of stroke. ${ }^{[6]}$ Several well-established modifiable risk factors for stroke, that is, hypertension (HTN), smoking, cardiac disease, diabetes, etc. Stroke appears to be a preventable disease to a large extent, ${ }^{[7,8]}$ change in lifestyle is supposed as the major primary prevention strategy. Lifestyle changes are likely to influence risk factor prevalence, which in turn may modify the stroke risk. ${ }^{[0]}$ The aim of the present study is to identify the prevalence of common modifiable risk factors (demographic and cardiovascular) for ischemic stroke in India. 


\section{MATERIALS AND METHODS}

\section{Study area and population}

The present epidemiological study is a retrospective 3 years, hospital-based study done in the Department of Neurosciences at Indraprastha Apollo Hospital, New Delhi, India, a total record of 244 patients admitted in the hospital during the period 01.01.2004-31.12.2006 were evaluated for incidence, risk factors (i.e., family history, history of smoking and coexisting diseases such as HTN, diabetes mellitus (DM), dyslipidemia, thromboembolic disorders and cardiac diseases) of ischemic stroke subtypes by a mechanism-based classification scheme (Trial of ORG 10172 in Acute Stroke Treatment [TOAST]) after the approval of institutional ethics committee. ${ }^{[10]}$

\section{Subtypes of ischemic stroke}

For the determination of the subtype of ischemic stroke, the original TOAST criteria were used. The 5 major categories of the TOAST classification are as follows: Large-artery atherosclerosis (LAA), including large-artery thrombosis and artery-to-artery embolism; cardio-embolism; small artery occlusion; stroke of other determined cause; and stroke of un-determined cause (UND). For strokes of un-determined origin, 1 of 2 explanations was needed:

a. No cause was found despite an extensive evaluation or

b. a most likely cause could not be determined because $>1$ possible cause was found.

The subtype definitions were based on risk factor profiles, clinical features, and results of diagnostic tests. The latter included computed tomography scan, magnetic resonance imaging, vascular imaging (carotid duplex, transcranial Doppler), electrocardiogram, echocardiography, assessment of prothrombotic syndromes, etc.

\section{Data and statistical analysis}

Variables were analyzed by finding their frequencies, percentages or odds ratio.

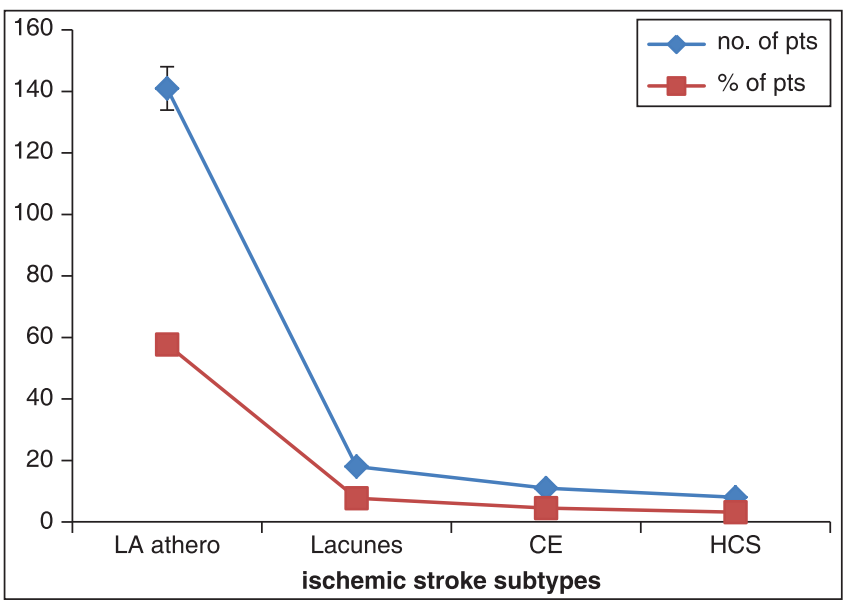

Figure 1: Determined cause of Ischemic stroke sub-types. $\mathrm{LA}$ athero, large artery atherosclerosis, CE = Cardioembolic, HCS $=$ Hypercoagulable state

\section{RESULTS}

A total of 91,500 patient was admitted at the Indraprastha Apollo Hospital, New Delhi, India, during the period of 3 years, between 01.01.2004 and 31.12.2006, out of which 361 had stroke (394.54/100,000), $244(0.26 \%, 266 / 100,000)$ were of ischemic stroke, evaluated for risk factors and stroke subtype.

\section{Demographic profile}

Out of 244 ischemic stroke patients, 165 (67.6\%) were male, and $79(32.4 \%)$ were female; mean age was $57.1 \pm 1.7$ years for all cases. Most of the patients included in the study belonged to middle class $185(75.8 \%), 27(11.1 \%)$ patients have the family history of stroke and $168(68.85 \%)$ were the sedentary workers [Table 1].

\section{Ischemic stroke subtype}

The incidence of ischemic stroke subtypes in present study were as follows, determined cause; LAA 141 (57.7\%), lacunes 18 (7.7\%), cardioembolic 11 (4.5\%), hypercoagulable state 8 (3.2\%) and UNDs; artherosclerotic and/or lacunes 25 (10.2\%), embolism and/or 2 more (hypercoagulable state/coronary artery disease $[\mathrm{CAD}])$ possible causes 7 (2.8\%), negative evaluation in $34(13.9 \%)$ patients [Table 2, Figures 1 and 2].

\section{Risk factor profile}

Different risk factors for ischemic stroke were, HTN $139(56.9 \%$, odds ratio 2.71); atherosclerosis 85 (61.15\%), lacunes $21(15.11 \%)$, atherosclerosis/lacunes $14(10.1 \%)$, negative evaluation in $19(13.67 \%)$, DM 85 (34.8\%, odds ratio 2.4); atherosclerosis 41 (47.67\%), lacunes 22 (25.88\%), atherosclerosis/lacunes $10(11.76 \%)$, negative evaluation in $12(14.12 \%)$, hyperlipidemia 58 (23.7\%, odds ratio 5.34$)$; atherosclerosis 28 (48.28\%), lacunes 12 (20.69\%), atherosclerosis/lacunes 8 (13.79\%), negative evaluation in 10 (17.24\%), smoking 95 (38.9\%, odds ratio $3.12)$; atherosclerosis 61 (64.21\%), lacunes $10(10.53 \%)$, cardioembolic $2(2.11 \%)$, atherosclerosis/lacunes $8(8.42 \%)$, negative evaluation in $14(14.74 \%)$, CAD 44 (18.0\%, odds ratio 1.43$)$; atherosclerosis 7 (15.90\%), lacunes 28 (63.64\%), atherosclerosis/lacunes 9 (20.45\%),

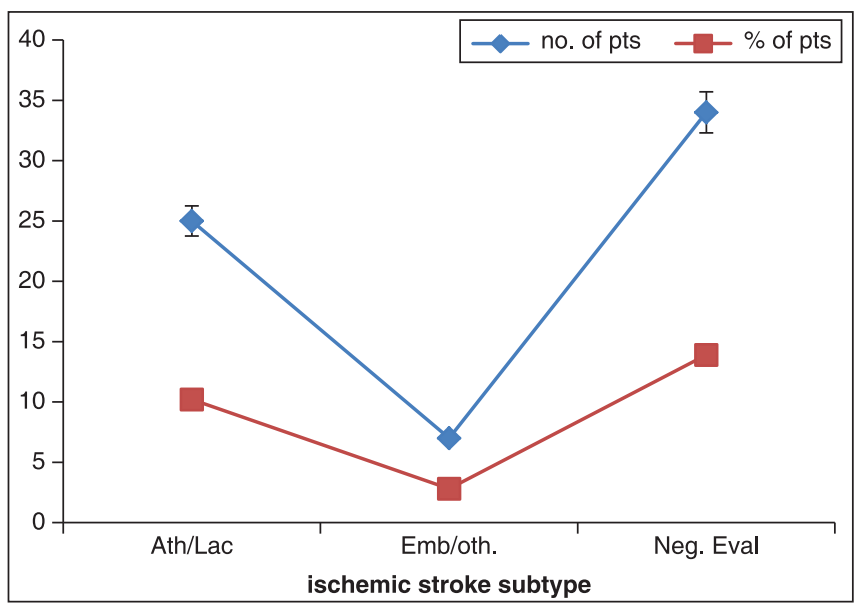

Figure 2: Un-determined cause of Ischemic stroke sub-types. Ath/ Lac, atherosclerosis/lacunes, Emb/oth, embolic/others, Neg.Eval, negative evaluations 
transient ischemic attack 14 (5.7\%, odds ratio 1.22); atherosclerosis 11 (78.57\%), lacunes 2 (14.29\%), atherosclerosis/lacunes 1 (7.14\%), atrial fibrillation 13 (5.3\%, odds ratio 1.43); cardioembolic 10 (76.92\%), emboli in 3 (23.08\%) [Tables 3 and 4, Figures 3 and 4].

\begin{tabular}{lc} 
Table 1: Demographic profile \\
\hline Parameter & Distribution of patients $(\boldsymbol{n}=\mathbf{2 4 4})(\%)$ \\
\hline Age (mean \pm SE) in years & $57.1 \pm 1.7$ \\
Sex & \\
$\quad$ Male & $165(67.6)$ \\
Female & $79(32.4)$ \\
Family history of stroke & $27(11.1)$ \\
SES & \\
Lower & $18(7.38)$ \\
Middle & $185(75.8)$ \\
Upper & $41(16.8)$ \\
Diet & \\
vegetarian & $117(47.95)$ \\
$\quad$ Nonvegetarian & $127(52.04)$ \\
Height (mean $\pm S E)$ in $\mathrm{cm}$ & $162.95 \pm 1.17$ \\
Weight (mean $\pm S E)$ in $\mathrm{kg}$ & $65.96 \pm 1.22$ \\
\hline
\end{tabular}

$\mathrm{SE}=$ Standard error, $\mathrm{SES}=$ Socioeconomic status

\begin{tabular}{lcc} 
Table 2: Subtypes of ischemic strokes & \\
\hline Category & $\begin{array}{c}\text { Number of } \\
\text { patients }\end{array}$ & Percentage \\
\hline Determined causes & 141 & 57.7 \\
Large artery atherosclerosis & 18 & 7.7 \\
Lacunes & 11 & 4.5 \\
Cardioembolic & 8 & 3.2 \\
Hypercoagulable state & 178 & 72.9 \\
Total & & \\
Un-determined Causes & 25 & 10.2 \\
Artherosclerotic and/or lacunes & 7 & 2.8 \\
Embolism among or more 2 possible & & \\
causes & 34 & 13.9 \\
Negative evaluation & 66 & 27 \\
Total & 244 & 100 \\
Grand total & & \\
\hline
\end{tabular}

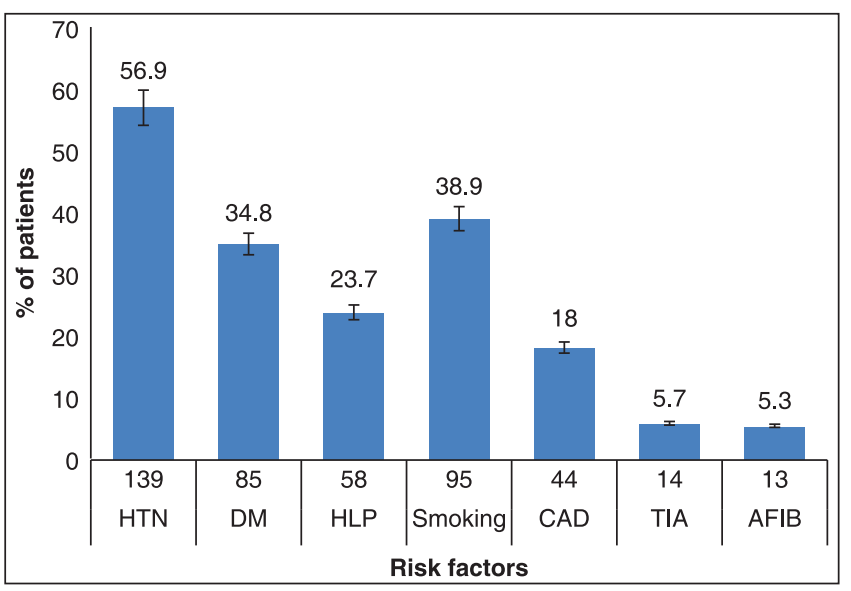

Figure 3: $\%$ for risk factors. HNT = Hypertension, DM = Diabetes mellitus, HLP = Hyperlipidemia, CAD = Coronary artery disease, $\mathrm{TIA}=$ Transient ischemic attack, $\mathrm{AFIB}=$ Atrial fibrillation

\section{DISCUSSION}

This is a retrospective epidemiological 3 years, hospital-based study on incidence and risk factor of ischemic stroke subtypes classified according to the TOAST criteria. The present hospital-based study used widely accepted standardized methods of case ascertainment and provided epidemiological data on causes of ischemic stroke in a section of Indian population.

Stroke is the main cause of adult disability and the second most leading cause of death worldwide. ${ }^{[3]}$ It is known that stroke incidence, prevalence and mortality vary widely in different populations. Studies such as the World Health Organization's Monitoring of trends and determinants of cardiovascular disease project have shown that relative to Caucasians, Asians have a higher prevalence of stroke. ${ }^{[1]}$ Stroke prevalence rate in our study is comparable to most of the earlier studies done in India 394.54/100,000 versus 136-350/100,000, ${ }^{[12-16]}$ except two studies which shows higher prevalence rate than the present study, Das et al., 2007 (545.10/100,000) and Bharucha et al., 1988 (842.3/100,000), the standardized rate in US is $424 / 100,000 .{ }^{[16]}$ Over the past few decades, the stroke prevalence rate has shown increasing trend in India 13 in $1970-350 / 100,000$ in $2004 .^{[14,15,17]}$ It may be attributed to the increasing incidence of HTN, DM, dyslipidemia, sedentary lifestyle, and change in dietary habits and lack of awareness regarding stroke risk factors. Study by Truelsen et al., in 2001 showed that the average age of stroke in developing countries is 15 years earlier than the developed world. ${ }^{[18]}$ The mean age of stroke in present study was $57.1 \pm 1.7$ years which is comparable to study done by Biswas et al., in 2009 (Indians) $64 \pm 10$ years versus (Americans) $71 \pm 13$ years. ${ }^{[19]}$ Stroke at earlier age has been shown by various studies conducted in India. ${ }^{[16,18,20]}$ Lipska et al., in 2007 showed that key components of metabolic syndrome and smoking are associated with ischemic stroke in South Indians. ${ }^{[1]}$ Many previous studies showed that the risk of stroke doubles for each successive decade after age 55 years. ${ }^{[22,23]}$

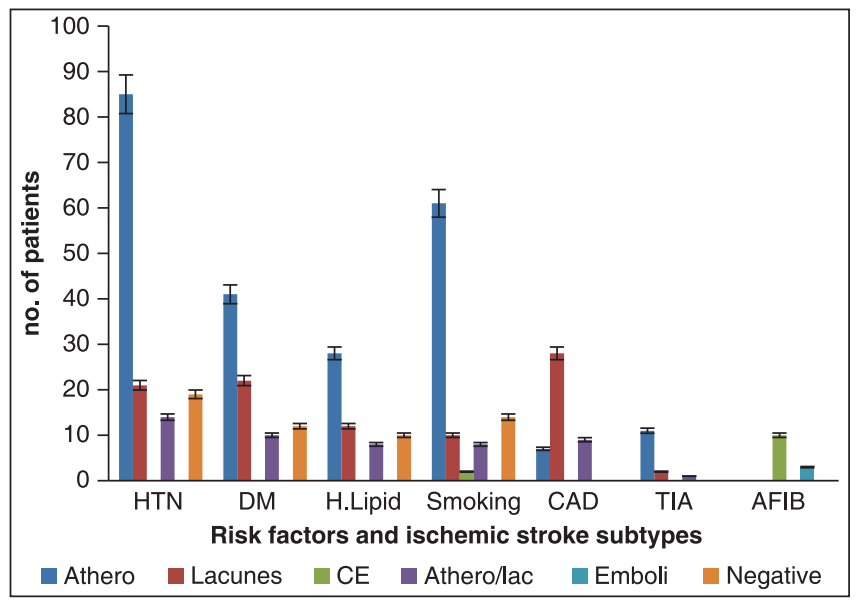

Figure 4: Risk factor profile of Ischemic stroke sub-types. HNT = Hypertension, DM = Diabetes mellitus, H.Lipid = Hyperlipidemia, $\mathrm{CAD}=$ Coronary artery disease, $\mathrm{TIA}=$ Transient ischemic attack, $\mathrm{AFIB}=$ Atrial fibrillation 


\begin{tabular}{lcccccc} 
Table 3: Risk factor profile & & & \\
Category & Athero $(\boldsymbol{n}=\mathbf{1 4 1})$ & Lacunes $(\boldsymbol{n}=\mathbf{1 8})$ & CE $(\boldsymbol{n}=\mathbf{1 1})$ & Athero/lacunes $(\boldsymbol{n}=\mathbf{2 6})$ & Emboli $(\boldsymbol{n}=\mathbf{7})$ & Negative $(\boldsymbol{n}=\mathbf{2 7})$ \\
\hline HNT & 85 & 21 & - & 14 & - & - \\
DM & 41 & 22 & - & 10 & - & 12 \\
HLP & 28 & 12 & - & 8 & - & 10 \\
Smoking & 61 & 10 & 28 & 9 & - & - \\
CAD & 7 & 2 & - & - & - & - \\
TIA & 11 & - & 10 & - & 3 & - \\
AFIB & - & - & - & - & - \\
\hline
\end{tabular}

HNT = Hypertension, DM = Diabetes mellitus, HLP = Hyperlipidemia, CAD = Coronary artery disease, $\mathrm{TIA}=$ Transient ischemic attack, AFIB = Atrial fibrillation, $\mathrm{CE}=$ Cardio-embolism

\begin{tabular}{lccc} 
Table 4: Percentage for risk factors \\
\hline Category & $\begin{array}{c}\text { Total } \text { number of } \\
\text { patients }(\boldsymbol{n}=\mathbf{2 4 4})\end{array}$ & Percentage & $\begin{array}{c}\text { Odds } \\
\text { ratio }\end{array}$ \\
\hline HTN & 139 & 56.9 & 2.71 \\
DM & 85 & 34.8 & 2.4 \\
HLP & 58 & 23.7 & 5.34 \\
Smoking & 95 & 38.9 & 3.12 \\
CAD & 44 & 18.0 & 1.43 \\
TIA & 14 & 5.7 & 1.22 \\
AFIB & 13 & 5.3 & 1.43
\end{tabular}

HNT = Hypertension, DM = Diabetes mellitus, HLP = Hyperlipidemia, $C A D=$ Coronary artery disease, $\mathrm{TIA}=$ Transient ischemic attack, AFIB = Atrial fibrillation

Hypertension affects millions of people worldwide and is a major risk factor for both cerebral infarction and intracerebral hemorrhage, Wolf 1999; Fields et al., 2004. ${ }^{[24,25]}$ The higher the blood pressure, greater will be a stroke risk, Lewington et al., 2002. ${ }^{26]}$ Chobanian et al., 2003 reported that control of high blood pressure contributes to the prevention of stroke as well as to the prevention or reduction of other target organ damage, including congestive heart failure and renal failure. ${ }^{[27]}$ Risk of stroke can be reduced by at least 38\% by control of HTN MacMahon and Rodgers 1996. ${ }^{[28]}$ HTN as a risk factor was present in $56.9 \%$ of our patients which was almost similar to $62 \%$ by Wu et al., $2010^{[29]}$ but $<72 \%$ and $85 \%$ reported in United States Sacco et al., 1998 and Russia Feigin et al., 1998 respectively. ${ }^{[30,31]}$

The role of dyslipidemia in the pathogenesis of cerebrovascular disease in less certain than for CAD; more consistent association has been noted with low high-density lipoprotein (HDL) cholesterol and high total cholesterol to HDL cholesterol ratio than with total cholesterol, low-density lipoprotein cholesterol and triglycerides. ${ }^{[32]}$ Dyslipidemia was present in $23.7 \%$ of our patients that slightly higher than the earlier studies from India. ${ }^{[12-16]}$ Higher prevalence of dyslipidemia in our stroke population could be attributed to the increasing trends of diabetes, HTN, sedentary lifestyle, excessive alcohol use and smoking.

Diabetes was a risk factor in $34.8 \%$ of cases in present study which is comparable to the studies done by Wu et al., 2010 (32.2\%), and by Lai et al., 2008 (36.9\%). ${ }^{[29,33]}$ Cigarette smoking is a potent risk factor for ischemic stroke. ${ }^{[34]}$ Present study recorded 38.9\% male patients with smoking which is lower than $53 \%$ reported by Wu et al., 2010, ${ }^{[29]}$ but higher than $31.3 \%$ reported by Lai et al., 2008. ${ }^{[33]}$ Smoking increases stroke risk by producing acute effects on the risk of thrombus generation in narrowed arteries and chronic effects related to an increased burden of atherosclerosis. ${ }^{[35]}$

Our study showed that large vessel occlusive disease was the most common cause of ischemic stroke (57.7\%), which is very high as compared to the available data from the developing countries indicate small vessel occlusion, is the most common cause of stroke, ${ }^{[36]}$ but similar with developed countries where the large artery disease is the most frequent reason for stroke. ${ }^{[29,37]}$ The relative proportion of large artery disease in different western stroke registries varies from $14 \%$ to $66 \% .{ }^{[37]}$ Variations in study designs, methods of patient selection and definitions of stroke subtypes may partially account for the wide variations in the reported frequency of large artery disease. Present study has shown $27 \%$ stroke of un-determined etiology, which is less than the previous studies done by Kolominsky-Rabas et al., $200135 \%$ and $44.4 \%$ by Wu et al., 2010..$^{10,29]}$ There are certain limitations, our study was conducted in a tertiary care referral center for neurological diseases and therefore be biased toward the more disabling and complicated disease processes, it was a retrospective collection of data from medical records, use of single occasion risk factors analysis and modest sample size.

To conclude, tobacco smoking and diabetes are growing problems in the developing countries. ${ }^{[38,39]}$ Our findings suggest that smoking, HTN, dyslipidemia and diabetes are the preventable stroke risk factors. Smoking cessation, prevention, identification and treatment of above-mentioned risk factors are crucial for preventing stroke. Further studies involving the multiple centers and more number of patients are required to substantiate our results.

\section{ACKNOWLEDGMENTS}

Author would like to thank to the administration of Indraprastha Apollo hospital, New Delhi for giving logistic support to complete such an extensive research work.

\section{REFERENCES}

1. Romero JR. Prevention of ischemic stroke: Overview of traditional risk factors. Curr Drug Targets 2007;8:794-801.

2. Williams GR. Incidence and characteristics of total stroke in the United States. BMC Neurol 2001;1:2.

3. American Heart Association. Heart Disease and Stroke Statistics-2009 Update. Circulation 2009;119:e21-181.

4. Murray CJ, Lopez AD. Mortality by cause for eight regions of the world: Global Burden of Disease Study. Lancet 1997;349:1269-76. 
5. Dávalos A. Thrombolysis in acute ischemic stroke: Successes, failures, and new hopes. Cerebrovasc Dis 2005;20 Suppl 2:135-9.

6. Leys D, Deplanque D, Mounier-Vehier C, Mackowiak-Cordoliani MA, Lucas C, Bordet R. Stroke prevention: Management of modifiable vascular risk factors. J Neurol 2002;249:507-17.

7. Kuller LH. Epidemiology and prevention of stroke, now and in the future. Epidemiol Rev 2000;22:14-7.

8. Sacco RL, Benjamin EJ, Broderick JP, Dyken M, Easton JD, Feinberg WM, et al. American Heart Association Prevention Conference. IV. Prevention and Rehabilitation of Stroke. Risk factors. Stroke 1997;28:1507-17.

9. Hu G, Sarti C, Jousilahti P, Peltonen M, Qiao Q, Antikainen R, et al. The impact of history of hypertension and type 2 diabetes at baseline on the incidence of stroke and stroke mortality. Stroke 2005;36: 2538-43.

10. Kolominsky-Rabas PL, Weber M, Gefeller O, Neundoerfer B, Heuschmann PU. Epidemiology of ischemic stroke subtypes according to TOAST criteria: Incidence, recurrence, and long-term survival in ischemic stroke subtypes: A population-based study. Stroke 2001;32:2735-40.

11. Thorvaldsen P, Asplund K, Kuulasmaa K, Rajakangas AM, Schroll M. Stroke incidence, case fatality, and mortality in the WHO MONICA project. World Health Organization Monitoring Trends and Determinants in Cardiovascular Disease. Stroke 1995;26:361-7.

12. Banerjee TK, Das SK. Epidemiology of stroke in India. Neurlo Asia 2006;11:1-4.

13. Saha SP, Bhattacharya S, Das SK, Maity B, Roy T, Raut DK. Epidemiological study of neurological disorders in a rural population of Eastern India. J Indian Med Assoc 2003;101:299-300, 302.

14. Das SK, Banerjee TK, Biswasl A, et al. A prospective community-based study of store in Kolkota, India. Stroke 2007;38:906-10.

15. Gourie-Devi M, Gururaj G, Satishchandra P, Subbakrishna DK. Prevalence of neurological disorders in Bangalore, India: A community-based study with a comparison between urban and rural areas. Neuroepidemiology 2004;23:261-8.

16. Bharucha NE, Bharucha EP, Bharucha AE, Bhise AV, Schoenberg BS. Prevalence of stroke in the Parsi community of Bombay. Stroke 1988;19:60-2.

17. Abraham J, Rao PS, Inbaraj SG, Shetty G, Jose CJ. An epidemiological study of hemiplegia due to stroke in South India. Stroke 1970;1:477-81.

18. Truelsen T, Bonita R, Jamrozik K. Surveillance of stroke: A global perspective. Int J Epidemiol 2001;30 Suppl 1:S11-6.

19. Biswas M, Sen N, Simmons J. Etiology and risk factors of ischemic stroke in Indian-American patients from a hospital-based registry in New Jersey, USA. Neurol Asia 2009;14:81-6.

20. Gupta R, Gupta VP, Sarna M, Prakash H, Rastogi S, Gupta KD. Serial epidemiological surveys in an urban Indian population demonstrate increasing coronary risk factors among the lower socioeconomic strata. J Assoc Physicians India 2003;51:470-7.

21. Lipska K, Sylaja PN, Sarma PS, Thankappan KR, Kutty VR, Vasan RS, et al. Risk factors for acute ischaemic stroke in young adults in South India. J Neurol Neurosurg Psychiatry 2007;78:959-63.

22. Brown RD, Whisnant JP, Sicks JD, O'Fallon WM, Wiebers DO. Stroke incidence, prevalence, and survival: Secular trends in Rochester, Minnesota, through 1989. Stroke 1996;27:373-80.

23. Wolf PA, D'Agostino RB, O'Neal MA, Sytkowski P, Kase CS, Belanger AJ, et al. Secular trends in stroke incidence and mortality. The Framingham Study. Stroke 1992;23:1551-5.
24. Wolf PA. Cerebrovascular risk. In: Izzo JL, Black HR, editors. Hypertension Primer: The Essentials of High Blood Pressure. Baltimore, Md: Lippincott, Williams and Wilkins; 1999. p. 239.

25. Fields LE, Burt VL, Cutler JA, Hughes J, Roccella EJ, Sorlie P. The burden of adult hypertension in the United States 1999 to 2000: A rising tide. Hypertension 2004;44:398-404.

26. Lewington S, Clarke R, Qizilbash N, Peto R, Collins R, Prospective Studies Collaboration. Age-specific relevance of usual blood pressure to vascular mortality: A meta-analysis of individual data for one million adults in 61 prospective studies. Lancet 2002;360:1903-13.

27. Chobanian AV, Bakris GL, Black HR, Cushman WC, Green LA, Izzo JL Jr, et al. The Seventh Report of the Joint National Committee on Prevention, Detection, Evaluation, and Treatment of High Blood Pressure: The JNC 7 report. JAMA 2003;289:2560-72.

28. MacMahon S, Rodgers A. Primary and secondary prevention of stroke. Clin Exp Hypertens 1996;18:537-46.

29. Wu CY, Wu HM, Lee JD, Weng HH. Stroke risk factors and subtypes in different age groups: A hospital-based study. Neurol India 2010;58:863-8.

30. Sacco RL, Gan R, Boden-Albala B, Lin IF, Kargman DE, Hauser WA, et al. Leisure-time physical activity and ischemic stroke risk: The Northern Manhattan Stroke Study. Stroke 1998;29:380-7.

31. Feigin VL, Wiebers DO, Nikitin YP, O'Fallon WM, Whisnant JP. Risk factors for ischemic stroke in a Russian community: A population-based case-control study. Stroke 1998;29:34-9.

32. Curb JD, Abbott RD, Rodriguez BL, Masaki KH, Chen R, Popper JS, et al. High density lipoprotein cholesterol and the risk of stroke in elderly men: The Honolulu heart program. Am J Epidemiol 2004;160:150-7.

33. Lai SL, Weng HH, Lee M, Hsiao MC, Lin LJ, Huang WY. Risk factors and subtype analysis of acute ischemic stroke. Eur Neurol 2008;60: 230-6.

34. Rodriguez BL, D'Agostino R, Abbott RD, Kagan A, Burchfiel CM, Yano K, et al. Risk of hospitalized stroke in men enrolled in the Honolulu Heart Program and the Framingham Study: A comparison of incidence and risk factor effects. Stroke 2002;33:230-6.

35. Burns DM. Epidemiology of smoking-induced cardiovascular disease. Prog Cardiovasc Dis 2003;46:11-29.

36. Feigin VL. Stroke epidemiology in the developing world. Lancet 2005;365:2160-1.

37. Sacco RL, Ellenberg JH, Mohr JP, Tatemichi TK, Hier DB, Price TR, et al. Infarcts of undetermined cause: The NINCDS Stroke Data Bank. Ann Neurol 1989;25:382-90.

38. Jha P, Chaloupka FJ. The economics of global tobacco control. BMJ 2000;321:358-61.

39. Woodward M, Zhang X, Barzi F, Pan W, Ueshima H, Rodgers A, et al. The effects of diabetes on the risks of major cardiovascular diseases and death in the Asia-Pacific region. Diabetes Care 2003;26:360-6.

How to cite this article: Renjen PN, Beg MA, Ahmad K. Epidemiological study of incidence and risk factors of Ischemic stroke subtypes according to Trial of ORG 10172 in acute stroke treatment criteria: A 3 years, hospital-based study. Int J Med Public Health 2015;5:50-4.

Source of Support: Nil, Conflict of Interest: None declared. 